\title{
The Research on Controlling Strategy of Rural Settlement Space in the Area Crisscrossed with Rivers of the Jianghan Plain
}

\author{
Min Wang ${ }^{1, a}$ \\ ${ }^{1}$ HuaZhong Agricultural University,NO.1 Shizishan Jie,Hongshan District,Wuhan City,Hubei \\ Province, China \\ awangmin009@mail.hzau.edu.cn
}

\begin{abstract}
Keywords: the Jianghan Plain, Rural Settlement, Spatial Controlling Strategy
Abstract. The development of rural settlements are facing great challenges because of rapid urbanization.Accompanied by the transformation of social economic structure,the contemporary rural settlement should be based on the comprehensive and coordinated development of the society and break through the traditional construction mode.In this paper, we put forward the optimization strategy of rural settlement spatial structure system in Jianghan Plain Area, promoting the spatial pattern of rural settlement in this region to develop in a good situation.It not only fill the insufficiency of current studies,but also is conducive to the development of rural settlement in the future and sustainable human living environment.
\end{abstract}

\section{Background}

The area crisscrossed with rivers of the Jianghan Plain is located in the south of Hubei Province,and is the core area of the middle reaches of the Yangtze River.This region is typical characteristics of water-town in the plain with numbers lakes and wetlands. With warm and humid climate,abundant precipitation and light energy,this region is the most important grain base in China.With the rapid urbanization the development and transformation of rural settlements the Jianghan Plain are facing great chances and challenges.Rice is the main food crops in Jianghan Plain,the next is wheat.Cotton is the main economic crop in this area.The earth of this area has deep layer and fertile soil,so the resource of cultivated land is very rich.Agricultural land accounts for $90 \%$ of the total area.

Recently the rapid urbanization promotes the development of economy and society in China.But on the other hand,the contradiction between urban and rural areas has become increasingly prominent because of the rural population and resources transferred and concentrated to towns. The Jianghan Plain is the most important grain base in China,so its development is related to national food security problem.At the same time it is also an important wetland area of Lake Ecological, with favorable natural ecological substrate.However many natural wetland communities have been destroyed recently,and the problem of fragility ecological environment is becoming more and more obvious.All in all,its development should be constructed rationally with both new and old, harmonious and unified.

\section{Significance}

In the process of rapid urbanization,the pattern of the landscape changes characterized by the continuous expansion of rural construction sites,large occupation of farmland, construction sites and farmland area increased risk of higher.Addition to the loss of rural labor force and the low level of agricultural technology,China food safety issues are also increasingly prominent.

Due to the transformation of social and economic,the mode of agricultural production has been changed,caused the lack of rural land resource.The first industry has became worse and worse.The research on spatial growth process of rural settlement space in the area crisscrossed with rivers of the Jianghan Plain has guidance to the coordinated development between land resources and agricultural production scale.It has a positive impact on the development of modern agricultural industry by 
means of a large-scale reorganization of agricultural resources.In addition,the optimization of village settlement space is adapted to the development of agricultural industry,which is conducive to improving the ability to resist risks of agricultural.Thus this measure can ensure the safety of national food production and have great significance to practice sustainable development in rural areas.

The research on the regulation of rural settlement space is the effective way to achieve the integration of urban and rural areas through the pattern optimization.It is of great significance to the study of rural settlement system theory under the contemporary background and to lay the foundation for the study of natural evolution pattern.Formulating rightly the development strategy in this region will have a positive impact on the comprehensive and coordinated development of the region.It is the necessary choice for the region improves general competitiveness to make this characteristic ancient area be full of vigor with sustainable development of human settlements.

\section{The Regulatory Controlling Strategies}

The regulation and controlling of settlement space is means that the location of rural settlements should be optimized through the ecological suitability evaluation and the structure analysis of water system.At the same time,the pattern of water system should be adjusted and then the river systems will be connected so that facilitate the convenient supply of water.It is also beneficial to the rural settlement become more balanced.

The implementation of ecological space management. The biotope pattern based on the improvement and protection of water system is the premise of the development of settlement space.The landscape pattern of "patch-gallery-matrix" is one of the basic principles of landscape ecology.As it for reference,drawing into the introduction of ecological pedal theory,the biotope pattern optimization and ecological space management will be actualized through the protection and planning of the urban habitat types.

To Protect the important ecological patches and yield its maximum ecological benefits;

To construct the green corridor and make biotope effective connected;

To optimize the farmland matrix and improve its comprehensive conditions;

To protect the farmland biotope and provide a favorable support for a variety of habitat patches;

To lead into the pivotal ecological pedal and make it connected with natural biotope.

It is necessary to protect the environment and develop tourism appropriately to further clarify the growth boundary of spatial development of rural settlement and prevent its disorderly development.We should ensure the biotope pattern based on the improvement and protection of water is the premise of the development of settlement space.The basis can be offered to the spatial layout of rural settlements by dividing of ecological space control area.

Strengthening the river and wetland remediation. The water system structure is the important influence factors of settlement space pattern.However with the development of urbanization in the settlement area,the distribution pattern of water system has been more and more chaotic,causing serious damage to the ecological environment. The improvement and optimization of the water system structure is the inevitable choice to actualize sustainable development of rural settlement.The water area of Jianghan Plain is 336896.13 hectares.It is the most concentrated area of the lake in Hubei province.

Remediation of water system can guide the development direction of settlement space and control the growth boundary of space; In accordance with the spatial pattern and regularity of natural river,the village layout should be minimized in flood area;The sustainability of river ecological system should be protected by controlling of rivers pollution and silting;And in the establishment of a complete network structure process,the layout of rural settlements should be regulated and controlled to meet the need of rural collective water supply.

Improving the arrangement of settlement space.In the hierarchical structure of the settlement space,the town is in the higher level of rural settlement unit with a certain degree of attraction and control force which affect the distribution, space function and form of the village.The town is a 
residential area between the city and the country with the perfect public service facilities and a large population and is the administrative economic center in this area.Based on the difference of space location and development resources,to define development of its scale and function is the key to form a new pattern of urban system as promoting the coordinated development of urban and rural areas.

Under the background of new urbanization,the function of town space has been changed from formerly only the town leading industry as the development direction of the positioning function.Now it was considered in a greater region of space,breaking through the limit of administrative boundaries and contradiction between urban and rural areas.Urban and rural integration development based on the linkage development of cities and towns is growing,with more abundant space level.The development of connotation and pattern of town not only has a greater impact on the level and layout of the settlement space,but also has played an active role to urban and rural overall planning.

Improving the distribution of central village.The central village is the basic unit of the urban and rural planning.It also is the basis of controlling and guiding the development of settlement space that effect the settlement space expansion.The whole optimization process is based on the certain spatial elasticity of the service area of central village. The rebuilding of human-land relationship system also must be based on meeting the foundation needs of people engaged in agricultural production. The basic service function of central village appears to be more important.Its service radius is at least not less than the radius of its farming in order to adapt to the basic needs of the surrounding grassroots village.

The regulation and guidance should clear the correlation between rural grassroots village and central village at first with determining spatial hierarchy correctly.And then is to form the center village as the core of the agglomeration settlement from the perspective of regional mutual development.The grassroots village is the most abundant and most widely distributed,and its spatial regulation should be according to the differentiation and transformation of village space.Through capital investment and policy support,the rural basic living environment and public service facilities are being in gradually perfect process.

Strengthening the control to the growth of Settlement border.The development of the combined form of the settlement space is one of the main contents of rural settlement pattern regulation.Controlling the spatial boundary of rural settlement can unified planning and management; Improving the internal form of rural settlement is to improve the construction of infrastructure and public services;To guide the combination form of rural settlement can engender the spacial order.

We should protect ecological environment and maintain the existing ecological boundary by means of ecological compensation and centralized relocation to protect the original village form and control the spread of its development.Through ecological protection,farmland consolidation and public infrastructure reconstruction, rural settlement pattern developed orderly with the optimization of spatial pattern of rural settlement.So that the whole space of rural settlement forms a certain space order and development potential under the premise of controllable development.

\section{Conclusions}

In China the research on rural settlement started late and had a tortuous development process.And compared with developed countries is still lagging behind.China is a vast country,so the characteristics, evolution, and development of vary regions are different.Single rural settlement development model can not cover all with the imbalance study in different regions of China.

The research on the village space in the area crisscrossed with rivers of the Jianghan Plain explore the relationship between people and the environment in a specific environment.On the hand it is the relationship between human and natural,on the other hand is the relation ship among man and society, economy and culture.Thus the research on rural settlement in China especially in the area crisscrossed with rivers of the Jianghan Plain,should grasp the background of different periods of growth and evolution of texture and analyze its spatial evolution and characteristics. 
The pattern optimization and control model adapted to its development should be put forward according to its regional characteristics considering adequately about the relationship between rural settlement and environmental characteristics, the internal spatial structure, social relations, economic relations, and the relationship with the environment.

As China's economy and modern city construction speed up steadily along with the rapid urbaniza -tion of country,the development of urban and rural dual structure caused a large of problems, with the urbanization development lagging behind.It leads to more and more big gap between the city and the countryside. Along with the construction of beautiful countryside advanced,the change of urban space caused by Circulation of Rural Land has become a hot and difficult topic about solving the “Three agriculture”Problems.

The implementation of controlling strategy of rural settlement space is an important way to solve the "Three agriculture" Problems. The implementation efforts will be strengthened through regulatory planning set.On the basis of coordinated regional development, diverse industrial development, employment opportunities increase and the training of talents,we should strengthen environmental protection,improve supervision system, and improving the life quality.Public participation can play a very important role to ensure the implementation of the results and form a regional characteristics of the settlement space system.The research on the optimization of spatial distribution of rural settlement has an important practice meanings in containing the expansion of construction land disorderly so that protecting arable land, especially basic farmland.

\section{References}

[1] Dj.M. Maric, P.F. Meier and S.K. Estreicher: Mater. Sci. Forum Vol. 83-87 (1992), p. 119

[2] M.A. Green: High Efficiency Silicon Solar Cells (Trans Tech Publications, Switzerland 1987).

[3] Y. Mishing, in: Diffusion Processes in Advanced Technological Materials, edtied by D. Gupta Noyes Publications/William Andrew Publising, Norwich, NY (2004), in press.

[4] G. Henkelman, G.Johannesson and H. Jónsson, in: Theoretical Methods in Condencsed Phase Chemistry, edited by S.D. Schwartz, volume 5 of Progress in Theoretical Chemistry and Physics, chapter, 10, Kluwer Academic Publishers (2000).

[5] Beizhen Xu:The Judgement of Landscape pattern evolution and ecological security in the Jianghan Plain,Central China Normal University(2012), in Chinese.

[6] R.J. Ong, J.T. Dawley and P.G. Clem: submitted to Journal of Materials Research (2003)

[7] P.G. Clem, M. Rodriguez, J.A. Voigt and C.S. Ashley, U.S. Patent 6,231,666. (2001)

[8] Information on http://www.weld.labs.gov.cn 